\title{
Modeling and Simulation for the AC-DC Electric Locomotive
}

\author{
Xiufang Jia, Zhe Liu \\ Department of electric power engineering, \\ North China Electric Power University, Baoding, \\ Hebei Province, 071000, China
}

\begin{abstract}
In recent years, with the rapid development of electrified railway, caused the number of AC-DC electric locomotive has a rapid growth. For power systems, electric locomotives as the non-linear loads, the harmonic problems caused by the electric locomotives have been increasingly important and get the widespread attention of the electricity workers. In this paper, we simplify the overall structure and analyze the working principle of the electric locomotive based on the AC-DC electric locomotives. And then the simulation model is established by the PSCAD/EMTDC simulation software to improve the managemant of the harmonic problems. Finally, the correctness and effectiveness of this model can be verified by comparing simulation data with the theoretical data and actual statistics.
\end{abstract}

Keywords-electric locomotive; simulation model; harmonic; PSCAD/EMTDC.

\section{INTRODUCTION}

With the rapid development of electrified railway, a large number of AC-DC electric locomotive has been used in the daily railway operation of our country. For supplying the power to electrified railway, a number of railway traction substation is built. As a single-phase rectifier load, the electric locomotive traction load fluctuated greatly. The characteristics, such as asymmetry, nonlinearity, volatility and wide distribution, make the electric locomotive has become an important harmonic source in our power system. As an important aspect of the power quality, the harmonic will endanger the safe operation of the utility grid, increase the power loss of the system, shorten the life of equipment, make the ground protection dysfunction, and make the equipment overheating.

As the power quality problems caused by the electrified railway get the widespread attention of the electricity workers, a large number of related study has been carried out. In [1], the simulation model is built based on the mathematical theory. But the simulation model is not the specific circuit component, and the parameters can not be adjusted flexibly in different conditions. According to the operation and operating characteristics, [2-3] simulate the changing process of the electric locomotive load in the electrification interval depending on the time and distance from the substation. The downside of the method is that the change of the feeder current in the different conditions is not considered. The dynamic simulation model of the eletrict locomotive can be established by MATLAB/SIMULINK in [4]. Through of current with FFT function from the DSP toolbox. Then the amplitude and phase angle of the fundamental and harmonic current injected into the catenary by the electric locomotive in the different voltage level, gear and speed can be obtained. Lack of this method is that simulation circuit can not adapt to different working sections. In this paper, take the $\mathrm{SS}_{6 \mathrm{~B}}$ electric locomotive as an example. We simplify the overall structure and analyze the working principle of the electric locomotive. And then the dynamic simulation model is established by the PSCAD/EMTDC simulation software. Finally, through the control module, the simulation of the electric locomotive model under the different working sections can be realized.

\section{MAIN CIRCUIT AND WORKING PRINCIPLE OF THE SS6B ELECTRIC LOCOMOTIVE}

\section{A. Main circuit of the $S S_{6 B}$ electric locomotive}

The power supply way of the $\mathrm{SS}_{6 \mathrm{~B}}$ electric locomotive is the independent bogie, that is, a bogie and three traction motors in parallel supplied by a main rectifier. Using asymmetric three and a half controlled bridge rectifier circuit, implement phased regulating, realize the constant current constant speed control of drawing speed characteristics. In this paper, take a bogie as an example to simulate. The main circuit can be shown as in Fig.1.

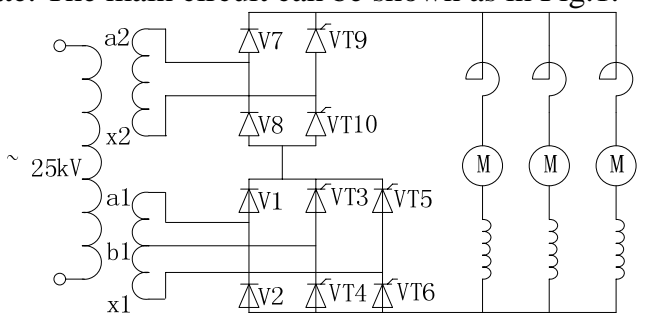

Fig.1. Main circuit

\section{B. Working principle of the SS6B electric locomotive}

In the asymmetric three and a half controlled bridge rectifier circuit, we can get the different rectified voltage and then adjust the output of the traction motor by conducting thyristors VT9 and VT10, VT3 and VT4, VT5 and VT6 in turn. The rated voltage of windings a2, x2 is $695.5 \mathrm{~V}$ and the rated voltage of windings $\mathrm{a} 1, \mathrm{~b} 1$ and $\mathrm{b} 1, \mathrm{x} 1$ is $347.75 \mathrm{~V}$. The work order of the circuit can be shown as follows:

The first work status: Firstly, put into the four-arm bridge, namely, conducting thyristors VT9 and VT10. Then put into windings a2, x2 and order phase shift of VT9 and VT10. The rectified voltage gradually rises from zero to $1 / 2 U_{\mathrm{d}}$. The second work status: put into the six-arm bridge 
when VT9 and VT10 are full open. And then conducting thyristors VT3 and VT4, put into windings a1, b1, order phase shift of VT3 and VT4. The rectified voltage gradually rises from $1 / 2 U_{\mathrm{d}}$ to $3 / 4 U_{\mathrm{d}}$. The third work status: onducting thyristors VT5 and VT6 when VT3, VT4, VT9 and VT10 are all full open. And then put into windings b1, $\mathrm{x} 1$, order phase shift of VT5 and VT6. The rectified voltage gradually rises from $3 / 4 U_{\mathrm{d}}$ to $U_{\mathrm{d}}$.

\section{SimUlATION MODEL OF SS6B ELECTRICAL LOCOMOTIVE BASED ON PSCAD}

In this paper, we constructed the simulation circuit based on the operating characteristic and the main circuit of the electric locomotive. It can be shown as in Fig.2.

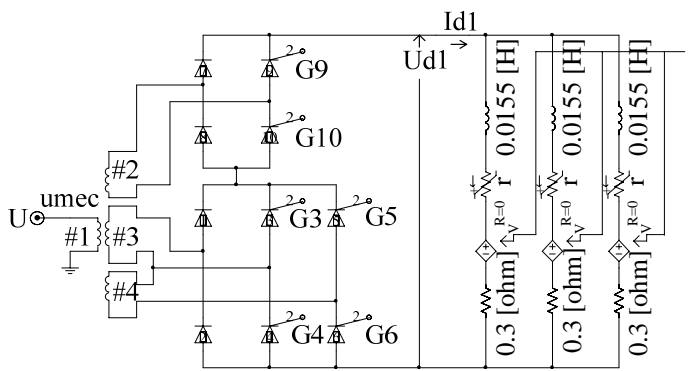

Fig.2. Simulation circuit

In this paper, the traction motor can be equivalent to the variable resistance $r$ and the controlled voltage source $E_{0}$ in series of combination, adjusted by the custom control module $E_{0} \& r$. Each parameter of the component in Fig.2 is taken as [5]. The DC voltage source and thyristor trigger pulse generating system should be established custom.

The traction control function of the $\mathrm{SS}_{6 \mathrm{~B}}$ electric locomotive can be shown as follow:

$$
I_{\mathrm{a}}=\left\{\begin{array}{c}
150 K \\
600 K-54 V \\
1100
\end{array}\right.
$$

Where: $K \longrightarrow$ Gear, from 1 to 10 ;

$V$ - Speed, $\mathrm{km} / \mathrm{h}$;

value of (1)

$I_{\mathrm{a}}$-Armature current, A, Take the minimum

Armature current is determined by the gear and speed. Then the DC-voltage of the rectifier circuit $U_{\mathrm{d}}$ can be obtained by (2)

$$
U_{\mathrm{d}}=I_{\mathrm{a}} R+E
$$

Where: $R$ - Total resistance of the rectifier circuit, include smoothing reactor, series resistance, armature winding, field winding, commutation pole winding and brush contact winding.
$E$ —_Back electromotive force of the traction motor.

When the effect of the magnetic saturation is considered, the magnetization curve of the traction motor is non-linear ${ }^{[4]}$. $E$ can be obtained by (3).

$$
E=C_{\mathrm{e}} n \phi
$$

Where: $C_{\mathrm{e}}-$ Motor constant;

$n-$ Motor speed, r/min;

$\varphi-$ Motor main pole flux, $\mathrm{Wb}$ 。

The magnetic flux in different current range can be obtained by (4).

$$
\phi= \begin{cases}1.19 \times 10^{-4} I_{f}+0.003 & 0<I_{f} \leq 400 \\ 6.95 \times 10^{-5} I_{f}+0.0228 & 400<I_{f} \leq 600 \\ 3.37 \times 10^{-5} I_{f}+0.04428 & 600<I_{f} \leq 1300\end{cases}
$$

Where: $I_{\mathrm{f}}$ Excitation current, A。

If the value of $U_{\mathrm{d}}$ can be determined, we can judge which status does the electric locomotive working in. According to the relatonship between rectifier circuit DC-voltage and the thyristor trigger angle, we can determine the trigger angle. The specific formula can be shown as (5) to (10).

In the first work status:

$$
\left\{\begin{array}{l}
\alpha_{10}=\arccos \left(\frac{\pi U_{d}}{\sqrt{2} U_{1}}-1\right) \\
\alpha_{10}=\alpha_{10}+180^{\circ}
\end{array}\right.
$$

Where: $U_{1}=695.5 \mathrm{~V}$, which is the rated voltage of the windings a2, $\mathrm{x} 2$.

In the second work status:

$$
\left\{\begin{array}{l}
\alpha_{4}=\arccos \left[\frac{\pi U_{d}}{\sqrt{2} U_{2}}-3-2 \times\left(1-\frac{2 I_{d} \times 0.001}{\sqrt{2} U_{1}}\right)\right] \\
\alpha_{3}=\alpha_{4}+180^{\circ}
\end{array}\right.
$$

Where: $U_{2}=347.75 \mathrm{~V}$, which is the rated voltage of the windings a1, b1.

In the third work status:

$$
\left\{\begin{array}{l}
\alpha_{6}=\arccos \left[\frac{\pi U_{d}}{\sqrt{2} U_{3}}-4-3 \times\left(1-\frac{2 I_{d} \times 0.001}{\sqrt{2} U_{1}}\right)+\frac{I_{d} \times 0.001}{\sqrt{2} U_{2}}\right] \\
\alpha_{5}=\alpha_{6}+180^{\circ}
\end{array}\right.
$$

Where: $U_{3}=347.75 \mathrm{~V}$, which is the rated voltage of the windings $\mathrm{b} 1, \mathrm{x} 1$.

\section{Simulation ANALYSIS}

In the different working status, the waveform of the 
rectifier voltage $U_{\mathrm{d} 1}$ and DC-side current $I_{\mathrm{d} 1}$ can be shown as in Fig.3, Fig.4 and Fig.5.
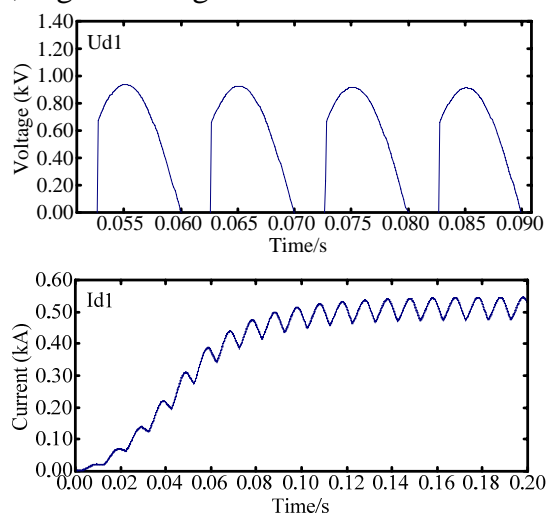

Fig.3. First work status
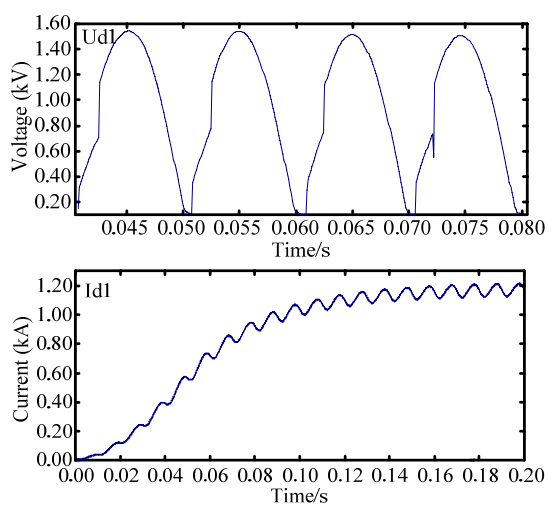

Fig.4. Second work status
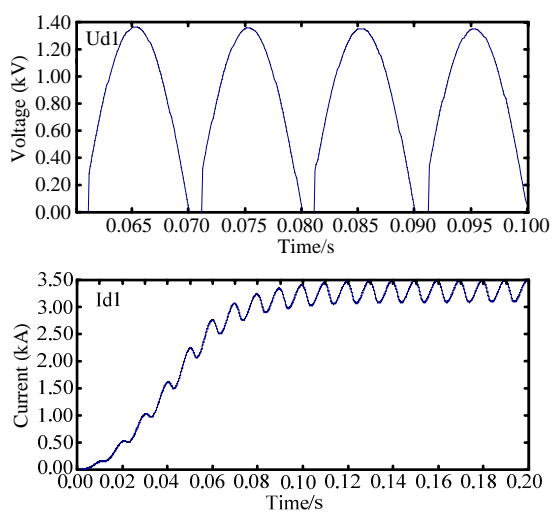

Fig.5. Third work status

As the role of smoothing reactors, the DC-side current $I_{\mathrm{d}}$ is ripple current. Since the characteristics which conducting the thyristors of the rectifier circuit in turn, it can be known that the rectified voltage waveform is consistent with the theoretical ${ }^{[7]}$.

In this paper, $K$ is taken as $8, V$ is taken as $68.5 \mathrm{~km} / \mathrm{h}$. The simulation is that the firing angle is $61.64^{\circ}$, in the third work status. Take the fast Fourier decomposition(FFT) for the electric locomotive harmonic current. The result can be shown as in Table 1.

TABLE 1. SIMULATION OF THE ELECTRIC LOCOMOTIVE HARMONIC CURRENT

\begin{tabular}{ccccccc}
\hline Harmonic number & 3 & 5 & 7 & 9 & 11 \\
& & & & & \\
Harmonic percentaeges/\% & 30.68 & 17.58 & 11.69 & 8.27 & 4.84
\end{tabular}

The actual statistic of the electric locomotive harmonic current is published in [6]. It can be shown as in Table 2.

TABLE 2. ACTUAL STATISTIC OF THE ELECTRIC LOCOMOTIVE HARMONIC CURRENT

\begin{tabular}{cccccc}
\hline Harmonic number & 3 & 5 & 7 & 9 & 11 \\
\hline $\begin{array}{c}\text { Harmonic percentaeges in } \\
\text { light load/\% }\end{array}$ & $26 \sim 30$ & $15 \sim 19$ & $10 \sim 12$ & $7 \sim 9$ & $4.5 \sim 5$ \\
$\begin{array}{c}\text { Harmonic percentaeges in } \\
\text { overload/\% }\end{array}$ & $5 \sim 9$ & $14 \sim 18$ & $9 \sim 11$ & $6 \sim 8$ & $3.5 \sim 4$ \\
\hline
\end{tabular}

The correctness and effectiveness of the model in this paper can be verified by comparing simulation data with the actual statistics.

\section{CONCLUSIONS}

In this paper, the electric locomotive simulation model is established based on the PSCAD/EMTDC simulation software. It can solve the problem that simulation modle can not adapt to different working sections based on MATLAB/SIMULINK and improve the managemant of the harmonic problems caused by electric locomotive.

The custom modules are used to implement the transformation control strategy of the electric locomotive in different working conditions.

\section{REFERENCES}

[1] Pile E,Rouse L,Fernandez A. A Simulation Tool for the Design of the Electrical Supply System of High-speed Railway Lines. Power Engineering Society Summer Meeting,2000(2):1053 1058

[2] Zhang Jinsi. Computer Simulation of Traction Load Process and Its Behaviour[J]. Journal of Southwest Jiaotong University, 1986.4

[3] Li Shuhui, Zhang Jinsi, Li Qunzhan. Traction Operation Simulation of SS3 Electric Locomotive[J]. Journal of the China Railway Society, 1993.6

[4] Zhao Juan, Li Jianhua, Huang Yongning. Simulation Model of SS3B Electric Locomotive Based on MATLAB/SIMULINK[J]. Electric Drive For Locomotive, 2002, 10(6): 25-26, 42

[5] Liu Youmei. SS6B Electric Locomotive[M]. Beijing: China Railway Publishing House, 2003.

[6] Lin Lei. Research of Adverse Effects on the Power Network Brought by Electric Railway System[D]. Zhejiang: Zhejiang University, 2004.

[7] Wang Zhaoan, Huang Jun. Power Electronics[M]. China Machine Press, 2012.6 